\title{
PENGARUH BRAND DESTINATION BERBASIS TRI HITA KARANA TERHADAP WORD OF MOUTH DAN NIAT BERKUNJUNG KEMBALI WISATAWAN KE NUSA PENIDA
}

\author{
Ni Nyoman Adityarini Abiyoga Vena Swara ${ }^{1}$ \\ Ni Luh Adisti Abiyoga Wulandari ${ }^{2}$ \\ I Gusti Ayu Wimba ${ }^{3}$
}

\author{
Fakultas Ekonomi, Bisnis dan Pariwisata Universitas Hindu Indonesia, Bali, \\ Indonesia ${ }^{1,2,3}$ \\ Email: adityarini.abiyoga @unhi.ac.id ${ }^{1,2,3}$
}

\begin{abstract}
The purpose of this study was to analyze the effect of Tri Hita Karana-based destination brand on word of mouth and the intention of returning tourists to Nusa Penida. As marinetourism, Nusa Penida waters are part of the world's coral triangle, while as spiritual tourism Nusa Penida is an area with strong spiritual vibrations so it is known as a secluded or sacred place. The research used descriptive and quantitative analysis with a total sample size of 100 tourists, both domestic and foreign who had visited Nusa Penida. The results of the study indicate that the Tri Hita Karana-based brand destination has a positive and significant effect on word of mouth and the intention to return to tourists to Nusa Penida. It is recommended that tourism development in Nusa Penida be carried out by collaborating traditional, social, cultural and local wisdom valueswhile maintaining harmonization of divine, human and environmental relationsas per the Tri Hita Karana philosophy
\end{abstract}

Keywords: Brand Destination; Word of Mouth; Intention to Revisit; Tri Hita Karana

\begin{abstract}
ABSTRAK
Tujuan penelitian ini adalah untuk menganalisis pengaruh brand destination berbasis Tri Hita Karana terhadap word of mouth dan niat berkunjung kembali wisatawan ke Nusa Penida. Sebagai wisata bahari, perairan Nusa Penida merupakan bagian dari segitiga terumbu karang dunia, sedangkan sebagai wisata spiritual Nusa Penida merupakan daerah dengan vibrasi spiritual yang kuat sehingga dikenal dengan tempat yang pingit atau sakral. Penelitian menggunakan analisis deskriptif dan kuantitatif dengan jumlah sampel sebanyak 100 orang wisatawan baik domestik maupun mancan negara yang sudah pernah berkunjung ke Nusa Penida. Hasil penelitian menyatakan bahwa brand destination berbasis Tri Hita Karana berpengaruh positif dan signifikan terhadapword of mouthdan niat berkunjung kembali wisatawan ke Nusa Penida. Disarankan dalam pengembangan pariwisata di Nusa Penida dilakukan dengan mengkolaborasikan nilai-nilai adat, sosial, budaya, dan kearifan lokal masyarakat dengan tetap menjaga harmonisasi hubungan ketuhanan, manusia, dan lingkungan sebagaimana filosofi Tri Hita Karana.
\end{abstract}

Kata Kunci: Brand Destination; Word of Mouth; Niat Berkunjung Kembali; Tri Hita Karana 


\section{PENDAHULUAN}

Pulau Bali sebagai salah satu destinasi wisata dunia memiliki keunikan dan keunggulan tersendiri yang membedakan Bali dengan destinasi wisata lainnya di dunia. Adanya perpaduan yang harmonis antara potensi adat istiadat, sumber daya manusia yang kreatif serta keindahan alam yang mempesona menjadi modal dasar untuk mengembangkan keunggulan kompetitif pariwisata di Pulau Bali. Pengembangan pariwisata di Pulau Bali telah mengalami kemajuan yang sangat pesat baik dari kualitas maupun kuantitas. Hal ini, dapat dilihat dari perkembangan sarana dan prasarana pariwisata seperti akomodasi, transportasi, fasilitas rekreasi, hiburan, komunikasi, dan atraksi wisata (Darsana, 2017). Salah satu destinasi wisata yang saat ini tengah dikembangkan di Pulau Bali adalah kawasan Nusa Penida.

Sebagai wisata bahari, perairan Nusa Penida merupakan bagian dari segitiga terumbu karang dunia, sedangkan sebagai wisata spiritual Nusa Penida merupakan daerah dengan vibrasi spiritual yang kuat sehingga dikenal dengan tempat yang pingit atau sakral. Pulau Nusa Penida atau yang sering di sebut sebagai Nusa Penida atau Nusa Gede disebut juga sebagi New Paradise Island atau pulau surga baru yang menyimpan begitu banyak keindahan. Nusa Penida menyimpan begitu banyak potensi wisata untuk di kembangkan mulai dari potensi wisata alam, budaya dan spiritual. Berikut data perkembangan jumlah kunjungan wisatawan yang berkunjung ke Nusa Penida selama Tahun 2014 sampai dengan 2018. 


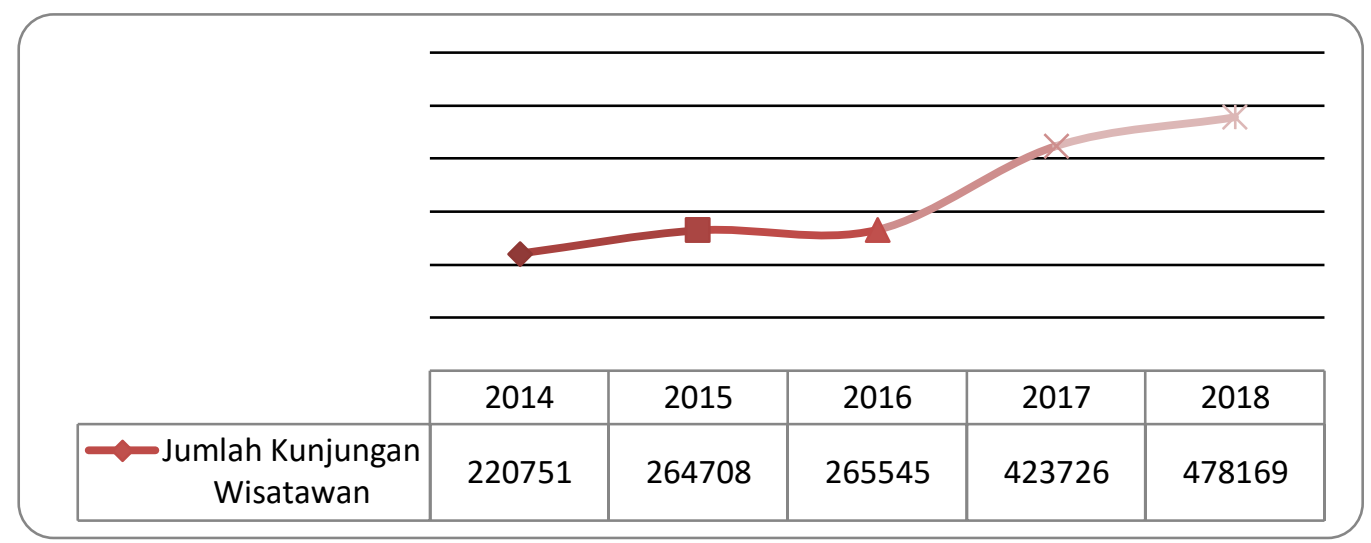

Sumber: Badan Pusat Statistik Kabupaten Klungkung, 2020

\section{Gambar 1}

Jumlah Kunjungan Wisatawan ke Nusa Penida Tahun 2014-2018

Berdasarkan data tersebut, terlihat bahwa jumlah kunjungan wisatawan ke Nusa Penida terus menerus mengalami peningkatan yang signifikan sepanjang tahun 2014 hingga tahun 2018. Melihat hal tersebut, pemerintah Provinsi Bali menjadikan Nusa Penida sebagai kawasan segitiga emas pariwisata Bali. Dimana menargetkan jumlah kunjungan wisatawan ke Nusa Penida di tahun 2019 mencapai 543.979 orang dengan target PAD sebesar 7 miliar Rupiah.

Pencapaian target kunjungan wisatawan tersebut tentunya memerlukan strategi pemasaran pariwisata yang tepat. Salah satunya melalui pengembangan sebuah identitas atau brand destination sebagai sebuah daerah tujuan wisata dengan mengedepankan nilai-nilai budaya dan kearifan lokal seperti Tri Hita Karana. Sebuah brand destinasi digunakan untuk memperkenalkan produk suatu destinasi wisata serta mengkomunikasikan keunikan destinasi tersebut secara visual, sehingga memudahkan destinasi untuk menjual produknya ke pasar pariwisata. Brand suatu destinasi haruslah mencakup keseluruhan destinasi yang 
didalamnya terdapat nilai, filosofi, budaya, serta harapan masyarakat atau stakeholder di dalam destinasi tersebut (Blain et al., 2005). Brand destination yang tepat harus mampu merubah persepsi wisatawan dari negatif ke positif yang sesuai dengan kebutuhan pengunjung untuk memberikan kemudahan dan memenuhi kebutuhan mereka selama berkunjung. Kotler (2009) menyatakan bahwa setiap lokasi juga dapat di "brand" kan dengan menciptakan dan mengkomunikasikan identitas bagi suatu lokasi yang bersangkutan.

Konsep Tri Hita Karana merupakan konsep yang sangat universal sehingga relevan pula diimplementasikan pada sektor pariwisata. Brand destination berbasis Tri Hita Karana akan membentuk persepsi dan citra yang positif dalam benak wisatawan. Selanjutnya dengan implementasi konsep brand destination berbasis Tri Hita Karana akan mempengaruhi strategi promosi atau komunikasi pemasaran yang dilakukan. Salah satu bentuk promosi dalam komunikasi pemasaran adalah word of mouth. Word of mouth menjadi referensi yang membentuk harapan pelanggan. Sebagai bagian dari bauran komunikasi pemasaran, word of mouth communication menjadi salah satu strategi yang sangat berpengaruh di dalam keputusan konsumen dalam menggunakan produk atau jasa (Hasan \& Setiyaningtiyas, 2015). Word of mouth yang kuat ditambah lagi dengan adanya dukungan media sosial dan internet yang saat ini berkembang pesat dimasyarakat luas, akan mendorong kesediaan konsumen untuk mengarahkan keputusan pembeliannya pada pembelian aktual. Efektivitas dan keberhasilan strategi branding dan komunikasi pemasaran dapat terlihat dari bersedia atau tidaknya wisatawan merekomendasikan destinasi wisata kepada wisatawan 
lainnya dan juga dapat terlihat dari kesediaan wisatawan untuk berkunjung kembali ke destinasi wisata tersebut.

Beberapa penelitian yang menjelaskan mengenai brand destinasi sebagai strategi pemasaran pariwisata seperti (Rahman \& Farida, 2017) yang menyatakan bahwa brand destination berpengaruh positif dan signifikan terhadap word of mouth dan niat berkunjung kembali wisatawan ke Objek Wisata Alam Goa Kreo Semarang. Penelitian lain oleh (George, 2004) menyatakan pula bahwa brand destinasi mempengaruhi perilaku wisatawan, dimana wisatawan cenderung memilih destinasi yang memiliki gambaran positif dan pada akhirnya mempengaruhi motivasi dan perilaku pengguna (wisatawan) itu sendiri. Sementara Wisansing (2005) dalam kajian terhadap pariwisata Malaysia juga menyatakan bahwa branding pariwisata dapat berhasil karena faktor: 1) brand yang kuat, 2) memiliki komitmen dan positioning yang kuat, 3) mampu mengembangkan pemasaran pariwisata, dan 4) memiliki produk pariwisata yang unik. Penelitian Popy (2007) yang mengkaji unsur-unsur dalam sebuah brand destinasi menyatakan bahwa sebuah brand destinasi terdiri dari unsur visual yang dilandasi oleh falsafah, kekayaan, jiwa, dan kelebihan/keunikan yang dimiliki oleh daerah tersebut.

Penelitian ini selanjutnya akan memasukkan konsep/filosofi Tri Hita Karana yang merupakan nilai-nilai kearifan lokal Bali pada pengembangan brand destinasi Nusa Penida menjadi sebuah identitas destinasi yang unik, sehingga dapat meningkatkan komunikasi dari mulut ke mulut (word of mouth) dan niat berkunjung kembali wisatawan ke Nusa Penida. 


\section{METODE PENELITIAN}

Penelitian menggunakan analisis deskriptif dan kuantitatif yang bermaksud menjelaskan kedudukan variabel-variabel yang diteliti serta hubungan antara variabel satu dengan variabel lain dan menguji hipotesis yang telah dirumuskan (Sugiyono, 2010). Populasi dalam penelitian ini adalah wisatawan domestik maupun mancanegara yang pernah berkunjung ke Nusa Penida. Sampel penelitian sebanyak 100 orang wisatawan yang ditemui secara kebetulan pada saat berkunjung ke Nusa Penida (accidental sampling). Metode pengumpulan data dilakukan dengan observasi, wawancara, studi pustaka, dan kuesioner. Instrumen penelitian di uji dengan uji validitas dan uji reliabilitas. Teknik analisis yang digunakan adalah analisis jalur (path analysis). Adapun model penelitian ini sebagaimana yang tergambar berikut ini.

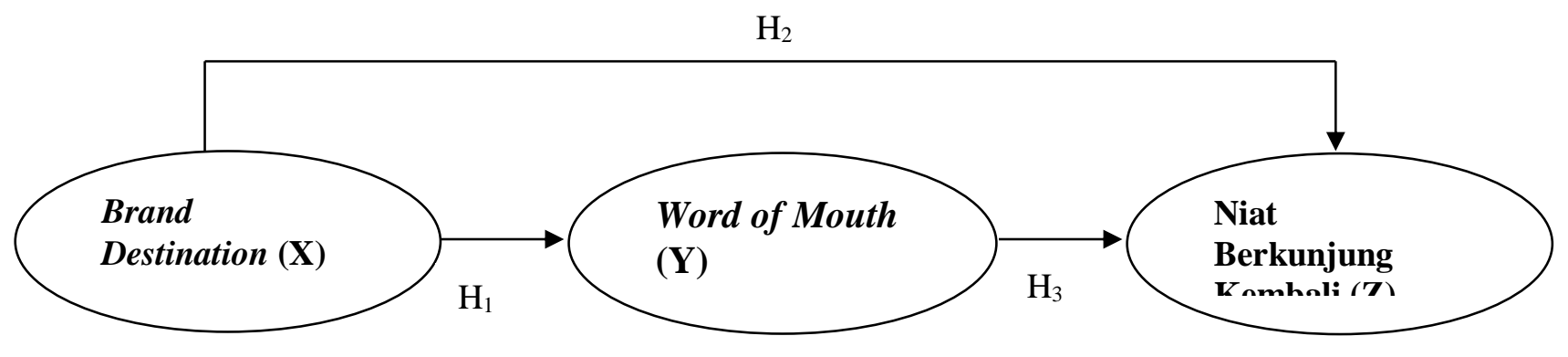

$\mathrm{H}_{4}$

\section{Gambar 2 \\ Model Penelitian Pengaruh Brand Destination Berbasis Tri Hita Karana Terhadap Word of Mouth dan Niat Berkunjung Kembali Wisatawan ke Nusa Penida}

Hipotesis penelitian: $\mathrm{H1}$ : diduga brand destination berpengaruh positif dan signifikan terhadap word of mouth wisatawan ; H2: diduga brand destination berpengaruh positif dan signifikan terhadap niat berkunjung kembali wisatawan 
ke Nusa Penida; H3: diduga word of mouth berpengaruh positif dan signifikan terhadap niat berkunjung kembali wisatawan ke Nusa Penida; H4: diduga word of mouth berperan memediasi pengaruh brand destination terhadap niat berkunjung kembali wisatawan ke Nusa Penida

\section{HASIL DAN PEMBAHASAN}

Pengujian data pada penelitian ini menggunakan analisis jalur (path analysis) guna menguji pola hubungan yang mengungkapkan pengaruh variabel atau seperangkat variabel terhadap variabel lainnya, baik pengaruh langsung maupun pengaruh tidak langsung. Pengujian dilakukan menggunakan analisis jalur (path analysis) melalui SPSS 23.0 diperoleh hasil sebagai berikut.

Substruktur 1:

$\mathrm{Y}_{1}=\beta_{1} \mathrm{X}_{1}+\mathrm{e}$

Dari hasil perhitungan pada pengujian data diperoleh hasil sebagai berikut.

Tabel 1

Pengujian Substruktur I

Coefficients $^{\text {a }}$

\begin{tabular}{|c|c|c|c|c|c|}
\hline \multirow[b]{2}{*}{ Model } & \multicolumn{2}{|c|}{$\begin{array}{l}\text { Unstandardized } \\
\text { Coefficients }\end{array}$} & \multirow{2}{*}{$\begin{array}{l}\text { Standardized } \\
\text { Coefficients } \\
\text { Beta }\end{array}$} & \multirow[b]{2}{*}{$\mathrm{t}$} & \multirow[b]{2}{*}{ Sig. } \\
\hline & $\mathrm{B}$ & Std. Error & & & \\
\hline 1 (Constant) & 6.410 & 5.835 & & 1.099 & .275 \\
\hline Branding & .752 & .088 & .653 & 8.527 & .000 \\
\hline
\end{tabular}

a. Dependent Variable: WOM

Sumber: data diolah, 2020

Substruktur 2:

$\mathrm{Y}_{2}=\beta_{1} \mathrm{X}+\beta_{2} \mathrm{Y}_{1}+\mathrm{e}$ 
Tabel 2

Pengujian Substruktur II

\section{Coefficients $^{\mathrm{a}}$}

\begin{tabular}{|c|c|c|c|c|c|c|}
\hline \multirow{2}{*}{\multicolumn{2}{|c|}{ Model }} & \multicolumn{2}{|c|}{$\begin{array}{l}\text { Unstandardized } \\
\text { Coefficients }\end{array}$} & \multirow{2}{*}{$\begin{array}{l}\text { Standardized } \\
\text { Coefficients } \\
\text { Beta }\end{array}$} & \multirow[b]{2}{*}{$\mathrm{t}$} & \multirow[b]{2}{*}{ Sig. } \\
\hline & & $\mathrm{B}$ & Std. Error & & & \\
\hline \multirow[t]{3}{*}{1} & (Constant) & 5.289 & 2.703 & & 1.956 & .053 \\
\hline & Branding & .309 & .054 & .40 & 5.761 & .000 \\
\hline & WOM & .349 & .047 & .52 & 7.493 & .000 \\
\hline
\end{tabular}

a. Dependent Variable: Niat Berkunjung Kembali

Sumber: data diolah, 2020

Berdasarkan perhitungan terhadap substruktur 1, dan 2, maka dapat diketahui besarnya pengaruh langsung, pengaruh tidak langsung dan pengaruh total antar variabel. Perhitungan pengaruh antar variabel adalah sebagai berikut:

Tabel 3

Pengaruh Langsung, Pengaruh Tidak Langsung, Pengaruh Total

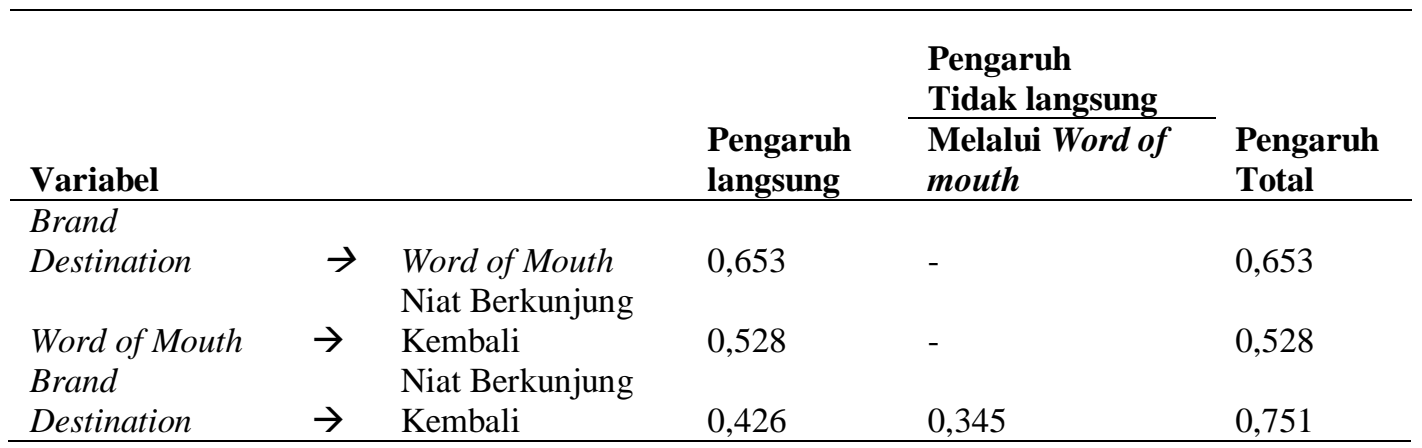

Sumber: data diolah, 2020

Berdasarkan hasil pengujian, terlihat bahwa pengaruh langsung dan pengaruh total variabel brand destination terhadap word of mouth adalah sebesar 0,653. Dimana pengaruh langsung brand destination terhadap niat berkunjung kembali adalah sebesar 0,426. Selain itu, pengaruh brand destination terhadap niat berkunjung kembali dimediasi oleh word of mouth yang memiliki pengaruh 
tidak langsung sebesar 0,345 sehingga pengaruh totalnya adalah 0,751 . Pengaruh langsung dan pengaruh total dari word of mouth terhadap niat berkunjung kembali adalah sebesar 0,528. Berikut gambar persamaan struktural untuk model penelitian ini adalah :

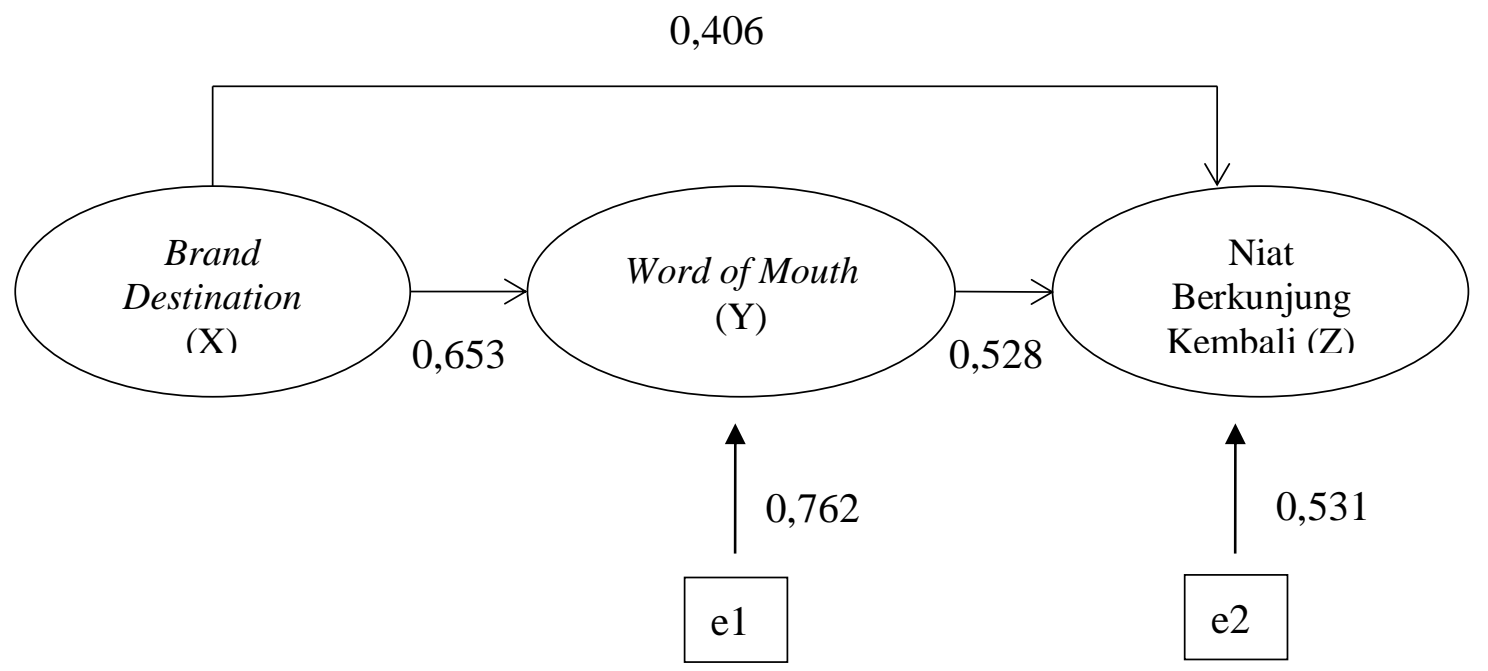

Gambar 3

Koefisien Jalur Brand Destination, Word of Mouth dan Niat Berkunjung Kembali

Pengaruh Brand Destination terhadap Word of Mouth Wisatawan. Hipotesis yang digunakan adalah sebagai berikut : $\mathrm{H}_{1}$ : Diduga brand destination berpengaruh positif dan signifikan terhadap word of mouth wisatawan Dengan kriteria uji sebagai berikut : Jika sig $\mathrm{t}<0,05$, maka $\mathrm{H}_{0}$ ditolak dan $\mathrm{H}_{1}$ diterima. Jika sig $\mathrm{t}>0,05$, maka $\mathrm{H}_{1}$ ditolak dan $\mathrm{H}_{0}$ diterima.

Berdasarkan hasil perhitungan diperoleh nilai t-hitung sebesar 8,527 dan taraf signifikansi penelitian untuk variabel brand destination terhadap word of mouth sebesar $0,000<0,05$, sehingga $\mathrm{H}_{0}$ ditolak dan $\mathrm{H}_{1}$ diterima, dengan kata lain 
brand destination berpengaruh signifikan terhadap word of mouth. Brand destinasi merupakan indikator value atau nilai yang ditawarkan kepada wisatawan, dimana brand menjadi aset yang memperkuat kepuasan dan loyalitas wisatawan terhadap destinasi wisata tersebut (Bungin, 2015:13). Untuk dapat membangun brand yang kuat dibutuhkan komunikasi pemasaran yang terintegrasi. Komunikasi merupakan jantung brand yang menggerakkan pesan janji-janji brand kepada konsumen.

Brand menjanjikan value terbaik kepada masyarakat, baik kualitas, layanan, kenyamanan, dan lain sebagainya. Komunikasi tersebut akan menggerakkan publisitas brand sehingga mencapai positioning di masyarakat, dan selanjutnya membentuk kesan atau image yang positif dimata konsumen (Rai Utama, 2016:219). Nusa Penida merupakan salah satu brand destinasi harus merepresentasikan nilai dan filosofi "Nusa Penida" sebagai tidak sekedar destinasi, tetapi juga budaya, filosofi, dam keseluruhan nilai-nilai kearifan lokal yang dimiliki oleh Nusa Penida.

Untuk itu memasukkan konsep Tri Hita Karana dalam membangun brand destinasi Nusa Penida akan memberikan keselarasan dan keharmonisan dalam pengembangan pariwisata berkelanjutan di Nusa Penida, sehingga akan memberikan pengaruh yang positif dalam segenap aspek mulai dari aspek lingkungan, sosial, budaya, dan juga aspek ekonomi.

Pengaruh Brand Destination terhadap Niat Berkunjung Kembali Wisatawan ke Nusa Penida . Hipotesis yang digunakan adalah sebagai berikut : $\mathrm{H}_{2}$ : Diduga brand destination berpengaruh positif dan signifikan terhadap niat 
berkunjung kembali wisatawan ke Nusa Penida. Dengan kriteria uji sebagai berikut : Jika sig $\mathrm{t}<0,05$, maka $\mathrm{H}_{0}$ ditolak dan $\mathrm{H}_{1}$ diterima. Jika sig $\mathrm{t}>0,05$, maka $\mathrm{H}_{1}$ ditolak dan $\mathrm{H}_{0}$ diterima.

Berdasarkan hasil perhitungan diperoleh nilai t-hitung sebesar 5,761 dan taraf signifikansi penelitian untuk variabel brand destination terhadap niat berkunjung kembali sebesar 0,000 $<0,05$, sehingga $\mathrm{H}_{0}$ ditolak dan $\mathrm{H}_{2}$ diterima, dengan kata lain brand destination berpengaruh signifikan terhadap niat berkunjung kembali wisatawan ke Nusa Penida.

Membangun brand destinasi yang kuat dengan memasukkan konsep Tri Hita Karana sebagai nilai-nilai kearifan lokal untuk menciptakan harmonisasi dalam pengembangan pariwisata tentunya akan memberikan kepuasan dan loyalitas kuat bagi wisatawan, yang mana ditandai dengan keinginan atau niat untuk melakukan kunjungan kembali ke destinasi wisata di masa mendatang. Destinasi pariwisata sebagai produk maupun pelayanan, memerlukan brand destinasi masing-masing agar dapat mengkonstruksi atau membentuk citra yang baik kepada wisatawan dan dapat menarik minat wisatawan untuk berkunjung dan berkunjung kembali ke destinasi wisata tersebut.

Pengaruh Word of Mouth terhadap Niat Berkunjung Kembali Wisatawan ke Nusa Penida. Hipotesis yang digunakan adalah sebagai berikut $: \mathrm{H}_{3}$ : Diduga word of mouth berpengaruh positif dan signifikan terhadap niat berkunjung kembali wisatawan ke Nusa Penida. Dengan kriteria uji sebagai berikut : Jika sig t $<0,05$, maka $\mathrm{H}_{0}$ ditolak dan $\mathrm{H}_{1}$ diterima. Jika sig $\mathrm{t}>0,05$, maka $\mathrm{H}_{1}$ ditolak dan $\mathrm{H}_{0}$ diterima. 
Berdasarkan hasil perhitungan diperoleh nilai t-hitung sebesar 7,493 dan taraf signifikansi penelitian untuk variabel word of mouth terhadap niat berkunjung kembali sebesar $0,000<0,05$, sehingga $\mathrm{H}_{0}$ ditolak dan $\mathrm{H}_{3}$ diterima, dengan kata lain word of mouth berpengaruh signifikan terhadap niat berkunjung kembali wisatawan ke Nusa Penida. Komunikasi pemasaran salah satunya dalam bentuk word of mouth merupakan bentuk komunikasi yang paling efektif untuk mendorong wisatawan berkunjung ke sebuah destinasi wisata.

Hal tersebut karena dalam word of mouth mengandung unsur interaksi dan kepercayaaan dari berbagi pengalaman yang dilakukan wisatawan yang telah berkunjung sebelumnya ke destinasi wisata tersebut. Berbagai ulasan yang positif mengenai Nusa Penida, kesediaan wisatawan untuk berbagi foto, gambar, dan aktivitas berwisata mereka saat berkunjung ke Nusa Penida, termasuk niat untuk merekomendasi dan mengajak teman, keluarga ataupun kerabat untuk berkunjung ke Nusa Penida menjadi hasil nyata dari bentuk komunikasi word of mouth tersebut.

Peran Word of Mouth Memediasi Pengaruh Brand Destination Terhadap Niat Berkunjung Kembali Wisatawan ke Nusa Penida. Hipotesis yang digunakan adalah sebagai berikut : $\mathrm{H}_{4}$ : Diduga word of mouth berperan memediasi pengaruh brand destination terhadap niat berkunjung kembali wisatawan ke Nusa Penida. Dengan kriteria uji sebagai berikut : Jika sig $\mathrm{t}<0,05$, maka $\mathrm{H}_{0}$ ditolak dan $\mathrm{H}_{1}$ diterima. Jika sig $\mathrm{t}>0,05$, maka $\mathrm{H}_{1}$ ditolak dan $\mathrm{H}_{0}$ diterima.

Berdasarkan hasil perhitungan diperoleh nilai sobel test sebesar 5,605 dan taraf signifikansi penelitian untuk variabel brand destination terhadap niat 
berkunjung kembali dengan mediasi word of mouth sebesar $0,000<0,05$, sehingga $\mathrm{H}_{0}$ ditolak dan $\mathrm{H}_{4}$ diterima, dengan kata lain word of mouth berperan memediasi pengaruh brand destination terhadap niat berkunjung kembali wisatawan ke Nusa Penida.

Dimana pengaruh tidak langsung word of mouth memediasi pengaruh brand destination terhadap niat berkunjung kembali wisatawan ke Nusa Penida yaitu sebesar 0,345 lebih kecil dibandingkan pengaruh langsung brand destination terhadap niat berkunjung kembali wisatawan ke Nusa Penida yaitu sebesar 0,426. Jika dimediasi oleh word of mouth, maka pengaruh total brand destination terhadap niat berkunjung kembali wisatawan ke Nusa Penida menjadi sebesar 0,751 .

Membangun brand destinasi dengan memasukkan konsep kearifan lokal dalam hal ini Tri Hita Karana akan memberikan nilai atau value tersendiri bagi eksistensi brand tersebut. Selanjutnya pengiklanan brand destinasi bertujuan untuk memperkenalkan produk destinasi untuk menjualnya di pasar pariwisata. Sebagaimana produk lainnya, untuk dapat menjual, maka produk selain dicitrakan melalui proses konstruksi sosial, produk juga harus dikomunikasikan kepada masyarakat. Brand destinasi yang kuat terbentuk dari komunikasi pemasaran yang kuat pula salah satunya dengan word of mouth, dimana brand destinasi yang kuat akan membangkitkan citra atau image di dalam pikiran wisatawan yang disertai harapan-harapan mereka.

Dimana komunikasi dari mulut ke mulut bertujuan mengajak orang untuk berpikir, merasakan dan bertindak dengan cara tertentu dalam hubungan 
mereka dengan brand. Tindakan yang diharapkan dari komunikasi pemasaran yang berhasil tentunya adalah kunjungan wisatawan bahkan bersedia melakukan kunjungan kembali dimasa mendatang, termasuk pula bersedia menggali informasi yang detail mengenai destinasi wisata, merekomendasikan, dan mengajak teman, keluarga dan kerabat untuk berkunjung ke destinasi wisata tersebut.

\section{SIMPULAN DAN SARAN}

Penelitian ini menyimpulkan beberapa hal dari hasil pengujian yang telah dilakukan yaitu (1) brand destination berbasis Tri Hita Karana berpengaruh signifikan terhadap word of mouth. Hal ini menunjukkan bahwa semakin baik dan kuat brand destinasi maka semakin kuat dan efektif pula komunikasi dari mulut ke mulut atau word of mouth, (2) brand destination berpengaruh signifikan terhadap niat berkunjung kembali wisatawan ke Nusa Penida. Hal ini menunjukkan bahwa semakin baik dan kuat brand destinasi maka semakin kuat niat wisatawan untuk berkunjung kembali ke Nusa Penida, (3) word of mouth berpengaruh signifikan terhadap niat berkunjung kembali wisatawan ke Nusa Penida. Hal ini menunjukkan bahwa semakin kuat word of mouth maka semakin kuat pula niat wisatawan untuk berkunjung kembali ke Nusa Penida, dan (4) Word of mouth berperan memediasi pengaruh brand destination terhadap niat berkunjung kembali wisatawan ke Nusa Penida.

Berdasarkan simpulan tersebut, berikut saran pengembangan pariwisata di Nusa Penida yaitu: (1) strategi komunikasi pemasaran destinasi wisata Nusa Penida dilakukan dengan mengintegrasikan aktivitas promosi dengan 
menonjolkan identitas wisata Nusa Penida yang memiliki, (2) melakukan penataan dan mempertahankan keasrian lingkungan dengan keterlibatan masyarakat lokal dan stakeholder lainnya. Termasuk juga pelestarian kawasan suci atau pura-pura yang menjadi objek wisata di Nusa Penida, (3) melakukan penataan sarana prasarana kepariwisataan yang tersedia di Nusa Penida untuk meningkatkan aksesibilitas dan juga memberikan pelayanan yang cepat dan mudah diakses oleh wisatawan dengan pemanfaatan teknologi digital, (4) mengembangkan produk daya tarik wisata yang lebih bervariasi dengan mengkolaborasikan nilai-nilai sosial, budaya, kearifan lokal dan lingkungan yang ada di Nusa Penida, (5) meningkatkan partisipasi masyarakat dan stakeholder dalam pengembangan destinasi wisata Nusa Penida melalui pemberdayaan masyarakat, peningkatan kualitas sumber daya manusia di sektor pariwisata, dan keterlibatan pemerintah yang aktif dalam memonitor, mengevaluasi dan akuntabilitas pembangunan pariwisata.

\section{REFERENSI}

Bungin, Burhan. 2015. Komunikasi Pariwisata, Pemasaran dan Brand Destinasi. Prenadamedia Group: Jakarta

Damayanti, Ida Ayu Kade, dkk. 2017. Strategi Pengembangan Pulau Nusa Penida Sebagai Kawasan Pariwisata yang Berkelanjutan. Soshum Jurnal Sosial dan Humaniora, 5(2). 1-10.

Darsana, I Wayan. 2017. Model Pengelolaan Wisata Bahari Berkelanjutan di Pulau Nusa Penida Kecamatan Nusa Penida Kabupaten Klungkung Bali. Jurnal Analisis Pariwisata, 17(1). 2-10

David, Aaker. 2017. Aaker On Branding: 20 Prinsip Esensial Mengelola dan Mengembangkan Brand. PT. Gramedia Pustaka Utama: Jakarta 
Dewi. 2011. Analisis Bisnis yang Berlandaskan Tri Hita Karana. Denpasar: Jurusan Sosial Ekonomi Pertanian, Fakultas Pertanian, Universitas Udayana.

Fill, Chris. 2013. Marketing Communication, Brand, Experiences and Participation, Sixth Edition. Harlow: Pearson

George, V. 2004. The Social Construction of Destination Image - a New Zealand Film Example. Bradford University School of Management. 2(1). 2-25.

Hankinson, G. 2004. The Brand Images of Tourism Destination: A Study of the Saliency of Organic Images. Journal of Product \& Brand Management, 13 (1), 6-14

Hasan, dan Setiyaningtiyas, 2015. Pengaruh Electronic Word of Mouth pada Media Sosial Facebook terhadap Keputusan Berkunjung ke Desa Wisata Nglanggeran Gunungkidul. Jurnal Media Wisata. 13(1). 1-10.

Heliany, Ina. 2019. Wonderful Digital Tourism Indonesia dan Peran Revolusi Industri Dalam Menghadapi Era Ekonomi Digital 5.0. Destinesia Jurnal Hospitaliti dan Pariwisata. 1(1). 21-35

Kotler, Philip dan Keller. 2009. Manajemen Pemasaran, Jilid I, Edisi Keduabelas, PT. Indeks, Jakarta.

Msi, Vellas, F., \& Becherel, L. 2008. Pemasaran Pariwisata Internasional: Sebuah Pendekatan Strategis. Jakarta: Yayasan Obor Indonesia

Rai Utama, I Gusti Bagus, Dr., MA. 2016. Pemasaran Pariwisata. Penerbit Andi: Yogyarakarta

Rahman dan Farida. 2017. Pengaruh Destination Branding dan Produk Wisata terhadap Niat Berkunjung Kembali melalui Word Of Mouth (Studi Kasus pada Objek Wisata Alam Goa Kreo Semarang). Jurnal Ilmu Administrasi dan Bisnis. 6(1). 61-67

Ruzzier, M.K.2010. Extending the Tourism Destination Image Concept Into Customer-Based Brand Equity For a Tourism Destination. Journal Ekonomska Istrazivanja, 23 (3), $24-42$

Wisansing, J. 2005. Components of Destination Branding: A Case of Malaysia

Yang, Y. 2010. The Construction of Brand Culture Based on Corporate Culture. International Journal of Business and Management, 5(4), 223 - 226 